\title{
PECULIARITIES OF CHANGES IN HOMOCYSTEINE LEVELS DEPENDING ON VITAMIN STATUS IN PATIENTS WITH CHRONIC PANCREATITIS AND TYPE 2 DIABETES
}

10.36740/WLek202101119

\author{
Yelyzaveta S. Sirchak, Vasilij Ye. Barani, Oksana I. Petrichko, Nelli V. Bedey \\ STATE HIGHER EDUCATIONAL INSTITUTION «UZHHOROD NATIONAL UNIVERSITY» UZHHOROD, UKRAINE
}

\begin{abstract}
The aim: To determine the peculiarities of changes in the homocysteine levels in the patients with chronic pancreatitis and type 2 diabetes blood serum depending on the vitamin status.

Materials and methods: We investigated 36 patients with chronic pancreatitis and type 2 diabetes, who were included in the first group of the patients examined; Group 2 consisted of 34 patients with chronic pancreatitis; and Group 3 of the patients examined consisted of 40 patients with type 2 diabetes.

Results: All patients examined were diagnosed with type 2 diabetes mellitus of moderate severity. Also, the diagnosis of chronic pancreatitis was confirmed in all patients with type 2 diabetes, which was manifested by exocrine pancreatic insufficiency according to the results of clinical, laboratory and instrumental methods of examination. There was a significant decrease in the level of all B vitamins and $25-(\mathrm{OH}) \mathrm{D}$ in patients with chronic pancreatitis and type 2 diabetes (Group I). An increase in the concentration of homocysteine in the serum in all examined groups of patients was established, with the maximum deviation from the norm in patients with chronic pancreatitis and type 2 diabetes (up to $32.7 \pm 0.8 \mu \mathrm{mol} / \mathrm{L}<0.01$ ). The correlation analysis revealed a strong direct relationship between the level of homocysteine and vitamins B12, B6, 25-(0H)D and an inverse correlation between vitamin $B 9$ in the group of patients with chronic pancreatitis and type 2 diabetes.

Conclusions: Patients with chronic pancreatitis and type 2 diabetes have a decreased levels of B vitamins (B1, B6, B9, B12) and 25-(OH)D, which is accompanied by an increase in serum homocysteine. In patients with chronic pancreatitis and type 2 diabetes, the level of homocysteine in the blood serum directly depends on the decrease in the levels of vitamins $B 6, B 12$ and $25-(\mathrm{OH}) \mathrm{D}$ in blood serum, as well as inverse depends on vitamin $B 9$ levels in these patients.
\end{abstract}

KEY WORDS: chronic pancreatitis, type 2 diabetes mellitus, vitamins, homocysteine

Wiad Lek. 2021;74(1):98-101

\section{INTRODUCTION}

Currently both diabetes mellitus (DM) and chronic pancreatitis (CP) pose a serious health and social problem due to the increasing prevalence and tendency towards progressive growth. The prognosis of diabetes and life expectancy are determined by the rate of development and progression of complications that occur as a result of diabetes. In this case, the higher the comorbidity in diabetes, the higher the risk of developing complications that aggravate each other [1].

Chronic pancreatitis is one of the most complex polyetiological and polymorbid diseases. The prevalence of $\mathrm{CP}$ among the population of different countries varies from $0.2 \%$ to $0.7 \%$ and reaches $6.0-9.0 \%$ among patients with gastrointestinal diseases [2]. Summation and potentiation of adverse effects of CP risk factors and causal factors contribute to the growth of $\mathrm{CP}$ incidence and its progressive course, with exocrine pancreatic insufficiency, development of maldigestion, malabsorption and trophological insufficiency in patients with impaired metabolism of all kinds $[3,4]$.

Studies of the pathogenesis of CP with multiple comorbidities prove the important role of such factors as systemic inflammation, imbalance of pro- and anti-inflammatory cytokines, factors of proteinase-inhibitory system with increasing negative effects of systemic proteolysis, violation of oxidant-antioxidant homeostasis with the activation of oxidative and nitrosive stress associated with natural antioxidants deficiency, hyperglycemia associated with the formation of pancreatogenic diabetes mellitus, which increases due to concomitant intestinal dysbiosis. The $\mathrm{CP}$ clinic with concomitant intestinal dysbiosis is complicated by increased intestinal dyspepsia, indigestion (steatorrhea, malabsorption of fat-soluble vitamins $\mathrm{D}$ and $\mathrm{K}$ and water-electrolyte imbalance) and astheno-vegetative syndrome caused by hypo- and avitaminosis, dysproteinemia and intoxication $[5,6]$.

Currently, the increase in homocysteine levels is given special attention due to the possibility of atherothrombotic, cerebral, cardiac and peripheral vascular disorders, as well as neurodegenerative processes [1]. Especially relevant is the study of homocysteine effect on the formation of complications, including vascular micro- and macroangiopathies in metabolically associated diseases, such as type 2 diabetes, especially in combination with CP.

Homocysteine is a sulfur-containing amino acid that is formed during the metabolism of methionine and cysteine. 
In the body, methionine is metabolized by demethylation, resulting in S-adenosylhomocysteine converted to homocysteine. The donor of the methyl group in this case is trimethylglycine (betaine). Another way of remethylation of homocysteine under the action of methionine synthetase is also possible. This reaction requires vitamin B12, which is a coenzyme of methionine synthetase. Homocysteine can also be catabolized in the process of trans-sulfurization by conversion to cysteine through cystathionine with the participation of the enzyme cystathionine-beta-synthetase, and the coenzyme required in this reaction is vitamin B6 [1].

Therefore, the study of vitamin status of the body and its possible impact on the level of homocysteine in patients with CP, especially in combination with type 2 diabetes is a topical issue in comorbid patient treatment.

\section{THE AIM}

To determine the peculiarities of changes in the homocysteine levels in the patients with $\mathrm{CP}$ and type 2 diabetes blood serum depending on the vitamin status.

\section{MATERIALS AND METHODS}

We investigated 36 patients with $\mathrm{CP}$ and type 2 diabetes, who were included in the first group of the patients examined (20 men (55.6\%) and 16 women $(44.4 \%)$ at an average age of $48.3 \pm 5,1$ years). Group 2 consisted of 34 patients with CP (21 men (61.8\%) and 13 women (38.2\%) at an average age of $46.7 \pm 4.2$ years); and Group 3 of the patients examined consisted of 40 patients with type 2 diabetes (22 men (55.0\%) and 18 women (45.0\%) at an average age of $48.9 \pm 6.3$ years). All examined patients were either hospitalized in the Endocrinology and Gastroenterology Departments of Municipal Non Profit Enterprise "Transcarpathian Regional Clinical Hospital Named After Andrii Novak" of Transcarpathian Regional Council or were on outpatient observation by the district family doctors at the place of their residence.

The control group included 20 healthy individuals (11 men (55.0\%) and 9 women (45.0\%) at an average age of $45.2 \pm 5.1$ years).

All studies were performed with the consent of the patients, and their methodology was in line with the Helsinki Declaration of Human Rights of 1975 and its revision of 1983, the Council of Europe Convention on Human Rights and Biomedicine and the current legislation of Ukraine.

All patients were examined sing general clinical, anthropometric, instrumental and laboratory research methods. All patients also underwent ultrasound examination of the abdominal cavity by conventional methods. Standard general and biochemical studies of blood serum were conducted with an emphasis on carbohydrate metabolism (glucose, glycosylated hemoglobin, insulin, C-peptide, proinsulin and glucose tolerance test).

All examined patients had their blood serum tested for $B$ vitamins, namely: vitamin B1 (thiamine) and vitamin B6 (pyridoxine) were tested by high performance liquid chromatography (HPLC) using Agilent 1100 Fluorescence Detector (Recipe Complete Kit, Germany); vitamin B9 (folic acid) was tested by immunochemical method with electrochemiluminescence detection (ECLIA Cobas 6000), using the test systems of Roche Diagnostics (Switzerland), and vitamin B12 (cyanocobalamin - holotranscobalamin) was tested using immunochemical chemiluminescent detection (CLIA Architect) with the test systems of Abbot Diagnostics (USA).

Studies of 25-hydroxyvitamin D, 25-(OH)D levels were performed to assess the status of vitamin $\mathrm{D}$ in the examined patients using an immunochemical method with electrochemiceluminescent detection (ECLIA Cobas 6000), using Roche Diagnostics test systems. The level $<20 \mathrm{ng} / \mathrm{mL}$ was evaluated as vitamin D deficiency; $20.0<30 \mathrm{ng} / \mathrm{mL}$ was considered insufficient, and the level $\geq 30 \mathrm{ng} / \mathrm{mL}$ was evaluated as optimal.

Serum homocysteine levels were also determined with Cobas 8000 test system (Roche Diagnostics).

The diagnosis of $\mathrm{CP}$ was established in accordance with the Marseille-Roman criteria (1989) with the addition of Ya.S. Zimmerman (1995) and clarifications of ICD-10. A coprological study was performed, serum amylase and fecal elastase- 1 levels were determined, and ${ }^{13} \mathrm{C}$-mixed triglyceride $\left({ }^{13} \mathrm{C}\right.$-CTDT) and ${ }^{13} \mathrm{C}$-amylase respiratory tests $\left({ }^{13} \mathrm{C}\right.$-ADT $)$ were used to study the exocrine function of the pancreas,.

Medical care was provided to the examined patients with diabetes according to the clinical protocols of the Ministry of Health of Ukraine and local protocols. The diagnosis of type 2 diabetes was established in accordance with the recommendations of the IDF (2005), as well as taking into account the criteria of a unified clinical protocol (The Ministry of Health of Ukraine Order of 21.12.2012 № 1118) $[7,8]$. The severity of type 2 diabetes was assessed by the level of HbA1c (Normal: up to 6.0\%).

The analysis and processing of the results of the examination was carried out by means of the STATISTICA 10.0 computer program (StatSoft Inc., USA) using parametric and nonparametric methods for evaluating the results.

\section{RESULTS AND DISCUSSION}

All patients examined were diagnosed with type 2 diabetes mellitus of moderate severity. Also, the diagnosis of chronic pancreatitis was confirmed in all patients with type 2 diabetes, which was manifested by exocrine pancreatic insufficiency according to the results of clinical, laboratory and instrumental methods of examination (data of coprological study, changes in serum amylase levels, fecal elastase ZTDT and ${ }^{13} \mathrm{C}-\mathrm{ADT}$ ).

Patients with $\mathrm{CP}$ and type 2 diabetes were tested for vitamin $\mathrm{B}$ and $25-(\mathrm{OH}) \mathrm{D}$ and serum homocysteine levels. The results are presented in table 1 .

There was a significant decrease in the level of all $\mathrm{B}$ vitamins and 25-(OH)D in patients with $\mathrm{CP}$ and type 2 diabetes (Group I). In particular, the most pronounced decrease was found in the levels of vitamins B9 and B12. Thus, they were reduced 4.7 and 3.5 times compared with 
Table 1. Changes in vitamin and homocysteine levels in the patients examined

\begin{tabular}{|c|c|c|c|c|}
\hline \multirow{2}{*}{$\begin{array}{c}\text { Indicator } \\
\text { (reference values) }\end{array}$} & \multirow[b]{2}{*}{ Control group } & \multicolumn{3}{|c|}{ Patients examined } \\
\hline & & $\begin{array}{l}\text { Group I } \\
(n=36)\end{array}$ & $\begin{array}{c}\text { Group II } \\
(n=34)\end{array}$ & $\begin{array}{c}\text { Group III } \\
(n=40)\end{array}$ \\
\hline $\begin{array}{l}\text { Vitamin B1, mcg/L } \\
\text { (over 49) }\end{array}$ & $73.2 \pm 2.4$ & $32.1 \pm 2.8 * *$ & $51.7 \pm 4.4{ }^{*},+$ & $41.3 \pm 3.2 *$ \\
\hline $\begin{array}{c}\text { Vitamin B6, mcg/L } \\
(8.7-27.2) \\
\end{array}$ & $18.5 \pm 1.7$ & $6.3 \pm 0.7^{* *}$ & $8.1 \pm 0.3 *$ & $7.7 \pm 0.5 *$ \\
\hline $\begin{array}{c}\text { Vitamin } B 9, \mathrm{ng} / \mathrm{mL} \\
(4.6-18.7)\end{array}$ & $14.5 \pm 0.9$ & $3.1 \pm 0.4 * *$ & $4.7 \pm 0.5 * *$ & $4.0 \pm 0.7^{* *}$ \\
\hline $\begin{array}{c}\text { Vitamin B12, pg/mL } \\
(197.0-771.0)\end{array}$ & $524.1 \pm 9.5$ & $\begin{array}{c}148.4 \pm 10.1 \\
* *\end{array}$ & $223.3 \pm 9.9 *,+$ & $186.8 \pm 9.4$ * \\
\hline 25-(OH)D, ng/mL, (over 30) & $47.2 \pm 2.7$ & $19.3 \pm 0.7^{*}$ & $23.1 \pm 1.4 *$ & $29.8 \pm 1.4+$ \\
\hline Homocysteine, $\mu \mathrm{mol} / \mathrm{L}$ (less than 15.0) & $9.7 \pm 0.6$ & $32.7 \pm 0.8 * *$ & $17.1 \pm 0.5{ }^{*},+$ & $24.3 \pm 0.5 *$ \\
\hline
\end{tabular}

Note: the differences between the indicators in the control group and the examined patients are significant: ${ }^{*} p<0.05$; ${ }^{* *} p<0.01$; differences between the indicators in the examined patients of Groups I and II are significant: $+p<0.05$.

Table 2. Comparison of $B$ vitamins with homocysteine levels in the examined patients

\begin{tabular}{cccc}
\hline \multirow{2}{*}{ Vitamins level } & \multicolumn{3}{c}{ Serum homocysteine levels } \\
\cline { 2 - 4 } & Group I & Group II & Group III \\
\hline Vitamin B1 & $r=0.46 ; p<0.05$ & - & - \\
\hline Vitamin B6 & $r=0.72 ; p<0.01$ & $r=0.58 ; p<0.05$ & $r=0.62 ; p<0.05$ \\
\hline Vitamin B9 & $r=-0.84 ; p<0.01$ & - & $r=0.44 ; p<0.05$ \\
\hline Vitamin B12 & $r=0.90 ; p<0.01$ & - & $r=0.84 ; p<0.01$ \\
\hline 25-(OH)D & $r=0.74 ; p<0.01$ & - & $r=0.58 ; p<0.05$ \\
\hline
\end{tabular}

this indicator of the control group $(\mathrm{p}<0.01)$. The levels of vitamins $\mathrm{B} 6$ and $\mathrm{B} 1$ were also lower compared to those in the control group -2.9 and 2.3 times, respectively $(\mathrm{p}<0.01)$.

In the comparison groups, more pronounced changes in the levels of $B$ vitamins were found among patients with type 2 diabetes (Group III). At the same time, the same tendency was observed as in patients of Group I, i.e. the maximum decrease in the level of vitamin B9 (3.6 times - $p$ $<0.01)$ and $\mathrm{B} 12(2.8$ times $-\mathrm{p}<0.05)$.

Patients with CP (Group II) also manifested a decrease in the concentration of $\mathrm{B}$ vitamins. In addition, it should be noted that the level of vitamin B9, although lower than in the control group $(4.7 \pm 0.5 \mathrm{ng} / \mathrm{mL}$ and $14.5 \pm 0.9 \mathrm{ng} /$ $\mathrm{mL}$, respectively, $\mathrm{p}<0.01$ ), did not go beyond the reference.

The analysis of vitamin D status in the examined patients also indicates its maximum decrease among patients of Group I (patients with CP and type 2 diabetes). It should be noted that the level of $25-(\mathrm{OH}) \mathrm{D}$ in the comparison groups was reduced more significantly in patients with $\mathrm{CP}$ (Group II) than with type 2 diabetes (Group III).

An increase in the concentration of homocysteine in the serum in all examined groups of patients was established, with the maximum deviation from the norm in patients with $\mathrm{CP}$ and type 2 diabetes (up to $32.7 \pm 0.8 \mu \mathrm{mol} / \mathrm{L}<0.01$ ).

The correlation analysis revealed a strong direct relationship between the level of homocysteine and vitamins B12, B6, $25-(\mathrm{OH}) \mathrm{D}$ and an inverse correlation between vitamin $\mathrm{B} 9$ in the group of patients with $\mathrm{CP}$ and type 2 diabetes (Table 2).
In patients with type 2 diabetes (Group III) a strong correlation was found only between homocysteine and vitamin B12, while the dependence of the average intensity was established between the levels of vitamins B6 and 25- $(\mathrm{OH}) \mathrm{D}$. For patients of Group II (patients with $\mathrm{CP}$ ) the dependence was only fond between changes in homocysteine and vitamin B6 levels.

Therefore, in patients with CP, especially in combination with type 2 diabetes there is a decrease in the level of both water-soluble (B vitamins - B1, B6, B9, B12) and fat-soluble $(25-(\mathrm{OH}) \mathrm{D})$ vitamins due to violation of exocrine insufficiency of the pancreas, malabsorption, as well as dysmetabolic disorders. Decreased levels of folic acid, pyridoxine, cyanocobalamin, which is one of the main substrates for the formation of homocysteine, contribute to its increase in blood serum. It is assumed that the deficiency of B vitamins with the subsequent development of hyperhomocyteinemia can trigger a cascade of vascular complications in patients with CP and type 2 diabetes. It is known that an increase in homocysteine levels is an independent risk factor for the development of different complication, including osteoporosis, indicated by a decrease in the level of $25-(\mathrm{OH}) \mathrm{D}$ in patients with CP type 2 diabetes combination.

\section{CONCLUSIONS}

1. Patients with $\mathrm{CP}$ and type 2 diabetes have a decreased levels of B vitamins (B1, B6, B9, B12) and 25-(OH)D, 
which is accompanied by an increase in serum homocysteine.

2. In patients with CP and type 2 diabetes, the level of homocysteine in the blood serum directly depends on the decrease in the levels of vitamins B6, B12 and 25-(OH) $\mathrm{D}$ in blood serum, as well as inverse depends on vitamin B9 levels in these patients.

\section{REFERENCES}

1. Davidchik E.V, Snezhickij V.A, Nikonova L.B. Interrelation of hyperhomocysteinemia with ischemic heart disease and diabetes mellitus. Journal of Grodno State Medical Universityю 2015; 1: 9-15.

2. Babinec L.S, Palihata M.V, Sasik G.M. Possibilities of complex rehabilitation of patients with chronic pancreatitis at the stage of primary care (literature review). Pancreatology Club Bulletin. 2018; May: 4-11. (in Ukrainian).

3. Raksha N.G, Halenova T.I, Vovk T.B, Sukhodolia S.A, Beregova TV, Ostapchenko LI. Proteolitic imbalance as a key factor of the development of chronic pancreatitis with and without type 1 diabetes mellitus. Visnik problem biologii i medicine. 2019; 3 (152): 186-191. (in Ukrainian) DOI 10.29254/2077-4214-2019-3-152-186-191

4. Hristich T.M, Hontsariuk D.0. Etiological factors which from the chronical pancreatitis. Zdobutki klinichnoji I eksperimentalnoji medicine. 2018; 3: 20-27. (in Ukrainian) DOl 10.11603/1811-2471.2018.v0.i3.9221

5. Kocaba Yu.Ya, Babinec L.S. Topical aspects of the use of probiotics in colonic dysbiosis. Family medicine. 2018; 4 (78): 85-87. (in Ukrainian)

6. Larin AS, Tkach SM. Phatogenetocheskaja rol kisechnogo disbioza v razvitii ozhirenia, insulinorezistentnosti I sacharnogo diabeta 2 tipa. Health of Ukraine. Thematic number. Gastroenterology. Hepatology. Coloproctology. 2016; 2 (40): 20-21. (in Russian).

7. Hobzej M.K, Guljchij M.V, Stepanenko A.V et al. Type 2 Diabetes Mellitus. Unified clinical protocol for primary and secondary (specialized) medical care. Kijiv; 2012. 118 p. (in Ukrainian). http://ukrgastro.com. ua/klinichni-protokoli-ta-nastanovi/

8. Hobzej M.K, Matyuha L.F, Netjazhenko V.Z et al. Type 2 Diabetes Mellitus. Adapted clinical guideline based on evidence. Kijiv; 2012. 343 p. (in Ukrainian).http://ukrgastro.com.ua/klinichni-protokoli-ta-nastanovi/
The scientific research was carried out within the scientific research work framework №851 "Mechanisms of the formation of complications in liver diseases and pancreas, methods of their treatment and prevention" (state registration number: 0115U001103), as well as the general department topic of the department of propaedeutics of internal diseases, as well as the scientific topic of the Department of Propaedeutics of Internal Medicine (Polymorbid pathology in diseases of the digestive system, features of pathogenesis, the possibility of correction (state registration number 0118U004365).

\section{ORCID and contributionship:}

Yelyzaveta S. Sirchak: 0000-0001-6738-0843 ${ }^{\text {A,B,E }}$

Vasilij Ye. Barani: 0000-0002-2616-2230 C,D

Nelli V. Bedey: 0000-0001-8044-0644 ${ }^{B C}$

Oksana I. Petrichko: 0000-0001-5420-6424 B,F

\section{Conflict of interest:}

The Authors declare no conflict of interest.

\section{CORRESPONDING AUTHOR Yelyzaveta S. Sirchak}

Head of the Department of Propedeutics of Internal Diseases,

State University «Uzhhorod National University»

Sqr. Narodna, 88000 Uzhhorod, Ukraine

tel: +380509761794

e-mail:sirchakliza777@gmail.com

Received: 13.08 .2020

Accepted: 28.12 .2020

A - Work concept and design, B - Data collection and analysis, C - Responsibility for statistical analysis, D-Writing the article, $\mathbf{E}$-Critical review, $\mathbf{F}$ - Final approval of the article 